\section{BIBLIOTECA JORGE D. WLLIAMS}

Separatum EXIPRIENTIA 18,563 (1962)
COLECCION HEREIULOGICA

$Y$ BIBLIOTECA

Ro dosè Miquel Cei

Birkhäuser Verlag, laasel (Schweiz)

\title{
Occurrence of Bradykinin-Like Substances in the Amphibian Skin ${ }^{1}$
}

Besides being an enormous store-house of indolealkylamines, phenylalkylamines and imidazolealkylamines, the amphibian skin appears to be an important production and/or storage site of highly active polypeptides.

One of them, physalaemin, has been clescribed in a preceding communication ${ }^{2}$. In this preliminary report, the occurrence of bradykinin-like substances will be briefly described. The term bradykinin-like should be interpreted in a broad sense.

So far about eighty amphibian species, collected in all parts of the world, but especially in South America, have been studied. High, and sometimes enormous, amounts of bradykinin-like compounds appeared to be present in methanol extracts of the skin of the examined Phyllomedusae (Phyl. sanvagi, Phyl. rhodei) and Ranae (R. esculenta, R. temporaria, R. pipiens, R. warschewitschii, R. japonica, R. catesbiana, R. nigromaculata).

The polypeptide nature of the active skin constituents is shown by their rapid and complete inactivation produced by chymotrypsin incubation, and by some preliminary results obtained following acid hydrolysis of the eluates of active paper chromatographic spots.

The accompanying Table presents the activity, expressed in terms of pure bradykinin, of crucle methanol extracts of the Phyllomedusa and Rana species examined. It should be emphasized that the figures are merely indicative of the relative potency of action possessed by the crude skin extracts on the different test-objects. Bradykinin served only as a standard substance, and very often the response to skin extracts was even qualitatively different from that given to bradykinin. In reality, all or nearly all aspects of the biological activity of crude Phyllomedusa or Rana extracts are due to a more or less complex mixture of active polypeptides. To elucidate the composition of this mixture, each extract should be studied separately and singularly. 


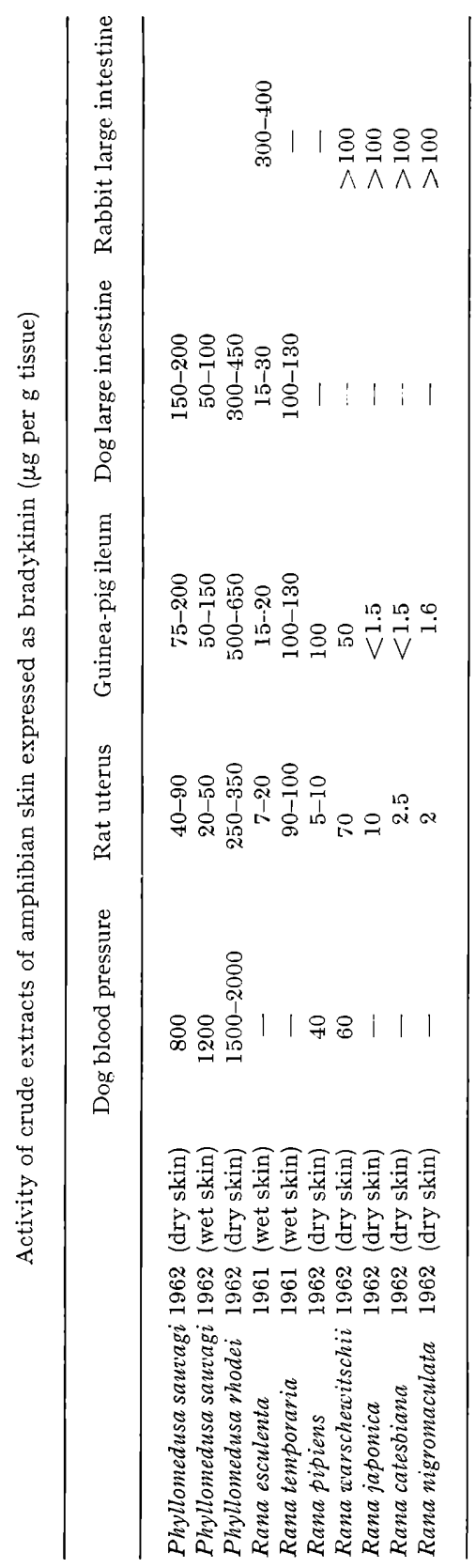


So far, a partial separation of the active constituents of crude skin extracts has been carried out for Phyllomedusa sauvagi and Phyllomedusa rhodei.

In a typical experiment, the residue left by evaporation of the methanol extract of $6 \mathrm{~g}$ fresh skin of Phyllomedusa sauvagi was dissolved in $95 \%$ ethanol and absorbed on an alkaline alumina column. Elution was carried out with descending concentrations of ethanol. At least three peaks of activity appeared in the eluates: the first in $70 \%$ ethanol (polypeptide A), the second in $60 \%$ ethanol (polypepticle B), and the third in $50-40 \%$ ethanol (polypeptide C).

Polypeptide A was the one that most strictly resembled bradykinin in its pharmacological properties. However, its identity with bradykinin is improbable.

Polypeptide B, perhaps the most interesting of the series, possessed a powerful hypotensive action in the dog and the rabbit. The fall of blood pressure which could be obtained with very low doses of the polypeptide, lasted considerably longer than that caused by bradykinin, substance $P$, eledoisin or physalaemin doses which produced a pressure fall of the same intensity.

Polypeptide $\mathrm{C}$ was particularly active on the guinea-pig ileum but the shape of the contraction curve differed sharply from that produced by bradykinin.

Polypeptides identical or similar to polypeptide A have been found in Phyllomedusa rhodei, Rana esculenta and Rana temporaria.

Research is in progress; intended to separate the different bradykinin-like polypeptides which have already been identified and which will be identified in the skin of the new amphibian species which we are collecting throughout the world, to determine their origin and significance, to subject the different polypeptides to a thorough pharmacological study, and finally to isolate the most abundant of them in a pure form in order to elucidate their chemical structure ${ }^{3}$.

Riassunto. Gli estrati di pelle di alcuni comuni anfibi nostrani (Rana esculenta, Rana temporaria) e, ancor più, di certi anfibi sudamericani del genere Phyllomedusa contengono rilevanti quantitativi di polipeptidi bradichinino-simili. Negli estratti di Phyllomedusa sauvagi ne sono stati identificati almeno tre, a mezzo di una semplice cromatografia su colonna di allumina basica: polipeptide A, assai simile alla bradichinina per le sue proprietà farmacologiche; polipeptide $B$, dotato di prolungata ed 
intensa azione ipotensiva; polipepticle $\mathrm{C}$, particolarmente attivo sull'ileo di cavia. Sono in corso ricerche dirette all'isolamento di questi polipeptidi e al chiarimento della loro struttura chimica.

V. Erspamer, G. Bertaccini, and J. M. Cei

Istituto di Farmacologia, Universitì di Parma (Italy) and Instituto de Biologia, Universidad Nacional de Cuyo, . Mendoza (Argentina), July 30, 1962.

1 Supported by grants from the Consiglio Nazionale delle Ricerche, Roma, and the Rockefeller Foundation, New York.

2 V. ERspanke, G. I3ertaccini, and J. M. Cei, Exper. 18, 562 (1962).

3 We are indebted to, and wish to thank I)r. N. URAKAwA (I)epartment of Veterinary l'harmacology, Faculty of Agriculture, Iniversity of Tokyo) for the specimens of Rana japonica, Rana catesbiana and Rana nigromaculata as well as for specimens of other Japanese amphibian species. A complete study of these species will be published in collaboration with I)r. Urakawa. 